\title{
The effects of a supplement of dietary fibre on faecal excretion by human subjects
}

\author{
BY CELIA J. PRYNNE* AND D. A. T. SOUTHGATE† \\ University of Cambridge and Medical Research Council, \\ Dunn Nutritional Laboratory, Milton Road, Cambridge
}

(Received 6 November 1978 - Accepted 6 December 1978)

\begin{abstract}
I. Four human subjects on strictly controlled diets were given a fibre supplement, $25 \mathrm{~g}$ Ispaghula husk (Isogel)/d, for 3 weeks.

2. Replicate diets and faeces were collected during two $5 \mathrm{~d}$ balance periods. The first period served as control for the second which occurred after the supplement had been fed for 2 weeks.

3. Diets and faeces were analysed for total solids, gross energy, total nitrogen, fat, available and unavailable carbohydrates.

4. Three of the four subjects showed a considerable increase in faecal bulk; total faecal weight was more than doubled in two subjects. In two subjects the increase was brought about mainly by extra fibre in the faeces accompanied by a higher proportion of faecal water whereas in one subject it was also an increased excretion of nutrients. One subject showed very little change in faecal bulk.

5. High values for the apparent digestibility of fibre were found during the control period; from 0.70 to 0.80 . There was more variation during the experimental period when apparent digestibility of total fibre ranged from 0.47 to 0.82 . Values arrived at for the minimum apparent digestibility of the fibre supplement were generally high; one subject appeared to digest Isogel completely. Isogel was degraded preferentially to the food-derived fibre; in particular, cellulose in the faeces was increased during the experimental period.

6. Only one subject showed distinct decreases in the apparent digestibility of energy, $N$ and fat in the diet. The results do not therefore agree with the generally held view that increased fibre in the diet decreases the apparent digestibility of the other nutrients.
\end{abstract}

It is generally agreed that an increased intake of fibre (dietary fibre as defined by Trowell et al. 1976) increases the bulk of the faeces. There is evidence from observations of people who customarily consume diets rich in unavailable carbohydrates (Burkitt et al. 1972), and from the results of experiments in which human subjects on controlled diets have been given supplements of various fibre preparations. These have included wheat bran (Eastwood et al. 1973; Jenkins et al. 1975) bagasse (Walters et al. 1975) and pectin (Durrington et al. 1976).

In the present study the fibre chosen was a water-soluble, non-cellulosic polysaccharide, Ispaghula husk, which is used pharmaceutically as a faecal-bulking agent. Preliminary analysis showed that this preparation contained very little other than fibre and that the principal component was a highly branched arabinoxylan (J. Singh, unpublished results). As the major non-cellulosic polysaccharide of wheat fibre is also an arabinoxylan (Norris \& Preece, 1930) the behaviour of the Ispaghula polysaccharide was of interest as a model substance. The advantage of using Ispaghula was that the fibre content of the diet could be increased without altering the composition of the remainder of the diet; an inevitable complication of feeding wheat-bran supplements.

The Ispaghula preparation was given to four human subjects and their response in terms of faecal bulk and hydration was examined. The extent to which both the foodderived fibre and the fibre supplement were degraded and metabolized during transit through the gut was also studied as this could throw light on the mechanism whereby the

* Present address: Bunda College of Agriculture, P.O. Box 259, Lilongwe, Malawi.

$\dagger$ Present address: ARC Food Research Institute, Colney Lane, Norwich. 


\begin{tabular}{|c|c|c|c|}
\hline $\begin{array}{l}\text { Subject } \\
\text { no. }\end{array}$ & Sex & $\begin{array}{c}\text { Age } \\
\text { (years) }\end{array}$ & $\begin{array}{c}\text { Weight } \\
(\mathrm{kg})\end{array}$ \\
\hline I & $q$ & $3 I$ & 63.9 \\
\hline 2 & q & 38 & $60 \cdot 3$ \\
\hline 2 & ô & 28 & $6 \times \cdot 5$ \\
\hline 4 & $\hat{O}$ & 31 & $82 \cdot I$ \\
\hline
\end{tabular}

effect of fibre on faecal bulk is exerted. The effect of the increased fibre on the apparent digestibility of the energy, nitrogen and fat in the diet was also examined.

\section{MATERIALS AND METHODS}

\section{Subjects}

The subjects were all volunteers from among the staff of the laboratory. They were all apparently healthy; their physical characteristics are shown in Table I. Preliminary interviews with the subjects revealed no eccentricities of diet; all usually consumed a typical British mixed diet which did not contain exceptional quantities of fibre-containing foods.

\section{Experimental design}

The subjects were observed over two separate 3 -week periods; the first period served as a control for the second, experimental, period. The first 2 weeks of each period were the 'run in' to the final week when a $5 \mathrm{~d}$ metabolic balance study was carried out. This lasted from Monday to Friday inclusive.

During the 'run in' subjects consumed their own usual diets but were asked to avoid all obvious high-fibre foods such as wholemeal bread, biscuits or breakfast cereals, and not to consume excessive quantities of fruits or vegetables. During the experimental period the subjects consumed $25 \mathrm{~g}$ Isogel (Allen \& Hanburys) each day. This was divided into three doses which were taken stirred into a carbonated drink.

The diets consumed during the $5 \mathrm{~d}$ balance periods were composed of typical British ingredients and contained a moderate quantity of fibre-containing foods. Great care was taken to ensure that the dietary constituents were as similar as possible during the two balance periods. The ingredients for breakfast were given to the subjects to be prepared and eaten at home. Lunch and dinner were prepared in the laboratory and these meals were eaten under supervision.

\section{Measurement of dietary intake}

All food and drink consumed in the laboratory were weighed or measured before consumption and exact replicates of everything consumed were collected. Quantities and descriptions of food and drink consumed outside the laboratory were recorded by the subject during the $5 \mathrm{~d}$ and duplicate collections were made up at the end of the week. Table salt, sugar, butter and marmalade were provided in containers which were weighed at the beginning and the end of the $5 \mathrm{~d}$ and quantities equivalent to that consumed were added to the duplicate collections. 


\section{Faecal collections}

Subjects were given gelatine capsules, each containing $500 \mathrm{mg}$ carmine; two of these were swallowed with breakfast on the Monday and two before retiring on Friday night. Faeces were collected from the start of the appearance of the first marker until the disappearance of the second. Faeces were delivered into polyethylene bags which were transferred immediately into insulated containers of solid carbon dioxide. The containers were brought to the laboratory each morning and the contents removed for storage at $-20^{\circ}$. These precautions were taken to reduce bacterial activity as far as possible.

\section{Preparation of samples for analysis}

The total duplicate daily diet collections were homogenized in a Braun liquidizer on the following day. Half of each homogenate was subsequently frozen and stored at $-20^{\circ}$ until dehydration in a freeze-drier (model EF6 Edwards). The faecal collections were also taken direct from the deep freeze for dehydration in the freeze-drier. The dried diets were crushed and, after thorough mixing, a portion (one-tenth) was taken to be ground by hand using a pestle and mortar. The dried faeces were also ground by hand, the fibrous particles being chopped up with stainless-steel scissors. The total collection was thoroughly mixed before taking samples for analysis.

\section{Analytical methods}

Total solids. These were estimated by weighing the samples after removal from the freezedrier.

Heat of combustion (gross energy). The heats of combustion of samples of freeze-dried diets and faeces were measured using a ballistic bomb calorimeter (Gallenkamp Ltd).

Total $N$. This was measured by the Kjeldahl method (G. J. Hudson \& P. M. V. John, unpublished results) using a semi-automated $\mathrm{N}$ system (Technicon AAII).

Fat. Dietary fat was measured by the method of Southgate (I97I). Faecal fat was measured by a modification by the official acid-hydrolysis method of the Association of Official Analytical Chemists (Southgate \& Durnin, 1970).

Carbohydrates. Starch, sugars and unavailable carbohydrates were measured by the method of Southgate (1969) using the modification described in Southgate (1976).

\section{RESULTS}

Fibre intake

The fibre intake of the subjects during the control and experimental periods is shown in Table 2. The non-cellulosic polysaccharide component of the fibre is described in terms of its constituent sugars; hexoses, pentoses, and uronic acids. The value for hexose:pentose of this fraction has been calculated which serves to describe its qualitative nature. The lignin content of these diets was so low as to be impossible to measure accurately.

The addition of Isogel to the diet more than doubled the total fibre intake during the experimental period, the increase being principally in the non-cellulosic polysaccharide contribution. The addition of this component altered the hexose:pentose value of the diet which was reduced from $3 \cdot 5-3.8$ to less than $\mathrm{I} \cdot 0$. This was due to the high pentosan content of Isogel. The cellulose content of the diet was very little changed by the addition of Isogel as the latter contains only a very small fraction that appears as cellulose by the method of analysis used.

Another change in the nature of the non-cellulosic polysaccharide consumed during the experimental period was the increase in the proportion that was water-soluble. 
Table 2. Dietary intake $(g / d)$ of unavailable carbohydrates by apparently healthy adult subjects during the control period and the experimental period when they were given Ispaghula husk (Isogel)

\begin{tabular}{|c|c|c|c|c|c|c|}
\hline \multirow[b]{2}{*}{ Subject* } & \multicolumn{3}{|c|}{ Non-cellulosic polysaccharide (NCP) } & \multirow{2}{*}{$\begin{array}{l}\text { Cellulose } \\
\text { hexose }\end{array}$} & \multirow{2}{*}{$\begin{array}{l}\text { Total } \\
\text { fibre }\end{array}$} & \multirow{2}{*}{$\begin{array}{l}\text { Hexose:pentose } \\
\text { for NCP }\end{array}$} \\
\hline & Hexose & Pentose & Uronic acids & & & \\
\hline IC & $8 \cdot 9$ & $2 \cdot 4$ & $3 \cdot 5$ & $5 \cdot 0$ & $19 \cdot 7$ & 3.7 \\
\hline$E$ & $13 \cdot 1$ & $17 \cdot 6$ & $5 \cdot 5$ & $6 \cdot 5$ & $42 \cdot 7$ & 0.74 \\
\hline $2 \mathrm{C}$ & $8 \cdot I$ & $2 \cdot 3$ & 3.5 & $4 \cdot 7$ & 18.6 & $3 \cdot 5$ \\
\hline $\mathrm{E}$ & 13.4 & 17.8 & $5 \cdot 6$ & $6 \cdot 0$ & $42 \cdot 7$ & 0.76 \\
\hline $3 \mathrm{C}$ & $10 \cdot \mathrm{I}$ & $2 \cdot 9$ & 4.0 & $5 \cdot 8$ & $22 \cdot 7$ & $3 \cdot 5$ \\
\hline $\mathrm{E}$ & $16 \cdot 1$ & 18.0 & $6 \cdot 4$ & 6.7 & $47 \cdot 3$ & 0.90 \\
\hline $4 \mathrm{C}$ & $8 \cdot 2$ & $2 \cdot 2$ & $3 \cdot 0$ & $4 \cdot 2$ & 17.6 & $3 \cdot 8$ \\
\hline $\mathrm{E}$ & $13 \cdot 1$ & 17.9 & $5 \cdot 3$ & $5 \cdot I$ & $4 I^{1} \cdot 4$ & 0.73 \\
\hline
\end{tabular}

C, Control; E, experimental.

* For details, see Table I.

Table 3. Faecal weight $(\mathrm{g} / \mathrm{d})$ over the $5 d$ balance period for apparently healthy adult subjects during the control period and the experimental period when they were given Ispaghula husk (Isogel)

\begin{tabular}{|c|c|c|c|c|c|c|}
\hline Subject* & $\begin{array}{c}\text { Total } \\
\text { wt }\end{array}$ & Difference & $\begin{array}{c}\text { Faecal } \\
\text { solids }\end{array}$ & Difference & $\begin{array}{c}\text { Faecal } \\
\text { water }\end{array}$ & Difference \\
\hline IC & 123 & $\ldots$ & 27 & - & 95 & - \\
\hline $\mathrm{E}$ & 286 & 163 & 62 & 35 & 224 & 129 \\
\hline $2 \mathrm{C}$ & I43 & 一 & 32 & - & II 2 & - \\
\hline $\mathrm{E}$ & 424 & $28 \mathrm{I}$ & 59 & 27 & 364 & 252 \\
\hline $3 \mathrm{C}$ & 224 & - & 48 & 一 & 175 & 二 \\
\hline $\mathrm{E}$ & 258 & 34 & 51 & 3 & 207 & 32 \\
\hline${ }_{4} \mathrm{C}$ & 158 & - & 41 & - & II 6 & - \\
\hline $\mathrm{E}$ & 253 & 95 & $5 I$ & 10 & 203 & 87 \\
\hline
\end{tabular}

Table 4. Faecal unavailable carbohydrates $(\mathrm{g} / \mathrm{d})$ for apparently healthy adult subjects during the control period and the experimental period when they were given Igpaghula husk (Isogel)

\begin{tabular}{|c|c|c|c|c|c|c|}
\hline \multirow[b]{2}{*}{ Subject* } & \multicolumn{3}{|c|}{ Non-cellulosic polysaccharide (NCP) } & \multirow{2}{*}{$\begin{array}{l}\text { Cellulose } \\
\text { hexose }\end{array}$} & \multirow{2}{*}{$\begin{array}{l}\text { Total } \\
\text { fibre }\end{array}$} & \multirow{2}{*}{$\begin{array}{l}\text { Hexose: pentose } \\
\text { for NCP }\end{array}$} \\
\hline & Hexose & Pentose & Uronic acids & & & \\
\hline IC & 1.6 & 0.8 & 0.6 & 0.9 & $3 \cdot 8$ & $2 \cdot I$ \\
\hline$E$ & 3.5 & 4.5 & 0.9 & 3.5 & $12 \cdot 3$ & 0.78 \\
\hline${ }_{2} \mathrm{C}$ & 1.6 & 0.8 & 0.6 & I. 3 & $4 \cdot 3$ & $2 \cdot 1$ \\
\hline $\mathrm{E}$ & 5.0 & 10.7 & 1.5 & 5.4 & $22 \cdot 6$ & 0.47 \\
\hline${ }_{3} \mathrm{C}$ & 2.4 & $1 \cdot 3$ & 0.9 & $1 \cdot 5$ & $6 \cdot 2$ & 1.8 \\
\hline $\mathrm{E}$ & 2.3 & 3.2 & 0.6 & $2 \cdot 5$ & $8 \cdot 6$ & 0.73 \\
\hline${ }_{4} \mathrm{C}$ & 1.9 & I. 0 & 0.8 & 1.6 & $5 \cdot 2$ & 1.8 \\
\hline$E$ & $2 \cdot 8$ & $7 \cdot 2$ & 0.6 & $2 \cdot 9$ & 13.5 & 0.38 \\
\hline
\end{tabular}


Table 5. Dietary intake and faecal excretion $(\mathrm{g} / \mathrm{d})$ of water-soluble non-cellulosic polysaccharide for apparently healthy adult subjects during the control period and the experimental period when they were given Ispaghula husk (Isogel)

\begin{tabular}{|c|c|c|c|}
\hline \multirow{2}{*}{$\begin{array}{c}\text { Subject } \\
\text { no.* }\end{array}$} & \multicolumn{3}{|c|}{ Non-cellulosic polysaccharide } \\
\hline & Hexose & Pentose & Uronic acids \\
\hline & \multicolumn{2}{|c|}{ Intake } & \\
\hline I C & $2 \cdot 7$ & $I \cdot 0$ & $\mathrm{I} \cdot 2$ \\
\hline $\mathrm{E}$ & $6 \cdot 6$ & $15 \cdot 3$ & $2 \cdot 9$ \\
\hline $2 \mathrm{C}$ & $2 \cdot 3$ & 1.0 & $1 \cdot 2$ \\
\hline $\mathrm{E}$ & $6 \cdot 5$ & $15 \cdot 5$ & $2 \cdot 9$ \\
\hline $3 \bar{C}$ & $2 \cdot 7$ & $I \cdot I$ & $\mathrm{I} \cdot 3$ \\
\hline $\mathrm{E}$ & $7 \cdot \mathrm{I}$ & $15 \cdot 3$ & $3 \cdot 1$ \\
\hline $4 \mathrm{C}$ & $2 \cdot 4$ & 0.9 & $I \cdot 2$ \\
\hline \multirow[t]{2}{*}{$\mathrm{E}$} & $6 \cdot 5$ & $15 \cdot 0$ & $3 \cdot 0$ \\
\hline & \multicolumn{2}{|c|}{ Excretion $\dagger$} & \\
\hline $\mathrm{IE}$ & - & 0.1 & $0 \cdot I$ \\
\hline $2 \mathrm{E}$ & $2 \cdot 1$ & 7.0 & 0.4 \\
\hline $3 E$ & 0.6 & 0.9 & 0.1 \\
\hline $4 \mathrm{E}$ & 0.7 & $4 \cdot 0$ & 0.2 \\
\hline
\end{tabular}

\section{Faecal weight and composition}

Table 3 shows the total faecal weight, weight of faecal solids and weight of faecal water during the control and experimental periods. The increase in each of these measurements during the experimental period is also shown. These increases were very much more marked in the female subjects but, whereas in subject no. I the proportion of faecal water was unchanged; the increase being matched by an increase in faecal solids, in subject no. 2 the proportion of faecal water rose from 0.78 to 0.86 . One of the male subjects, subject no. 4 , also showed a rise in the proportion of faecal water, from 0.74 to 0.80 but subject no. 3 showed very little change of any kind.

The fibre measured in the faeces is shown in Table 4. During the control period more than $70 \%$ of the ingested fibre disappeared during transit through the gut and the quantity found in the faeces was quite small. Faecal fibre was increased in all subjects during the experimental period but the extent of the increase varied greatly between individuals from $2.4 \mathrm{~g}$ in subject no. 3 to $18.3 \mathrm{~g}$ in subject no. 2. The most marked change in the nature of the faecal fibre during the experimental period was the increase in the pentose fraction of the non-cellulosic polysaccharide; this was greater in subject nos. 2 and 4 than in subject nos. I and 3. All the subjects showed an increase the faecal excretion of cellulose during the experimental period.

The faecal excretion of water-soluble non-cellulosic polysaccharide during the control period was so low as to be immeasurable, but a small proportion of this fibre fraction was measured in the experimental faeces and is shown in Table 5.

\section{Apparent digestibility of fibre}

The values are given in Table 6 . The digestibility of the fibre provided in the control diet was very high; in total between 0.70 and 0.80 , the 'worst-digested' component being the pentose fraction of the non-cellulosic polysaccharide. This was reflected by the downward shift in hexose:pentose in the faeces as compared with the diets. There was very little variation in the manner in which the four individuals behaved towards food-derived 
Table 6. Apparent digestibility of unavailable carbohydrates in apparently healthy adult subjects during the control period and the experimental period when they were given Ispaghula husk (Isogel)

\begin{tabular}{|c|c|c|c|c|c|}
\hline \multirow[b]{2}{*}{ Subject* } & \multicolumn{3}{|c|}{ Non-cellulosic polysaccharide } & \multirow{2}{*}{$\begin{array}{c}\text { Cellulose } \\
\text { hexose }\end{array}$} & \multirow{2}{*}{$\begin{array}{l}\text { Total } \\
\text { fibre }\end{array}$} \\
\hline & Hexose & Pentose & Uronic acids & & \\
\hline IC & 0.825 & 0.686 & 0.840 & 0.814 & 0.808 \\
\hline $\mathrm{E}$ & 0.736 & 0.745 & 0.843 & 0.467 & 0.712 \\
\hline $2 \mathrm{C}$ & 0.801 & 0.668 & 0.819 & 0.733 & 0.771 \\
\hline E & 0.628 & 0.398 & 0.730 & 0.101 & 0.472 \\
\hline $3 \mathrm{C}$ & 0.759 & 0.541 & 0.766 & 0.743 & 0.728 \\
\hline $\mathrm{E}$ & 0.858 & 0.824 & 0.902 & 0.626 & 0.819 \\
\hline $4 \bar{C}$ & 0.773 & 0.528 & 0.748 & 0.621 & 0.702 \\
\hline$E$ & 0.789 & 0.597 & 0.882 & 0.434 & 0.675 \\
\hline
\end{tabular}

C, Control; E, experimental.

* For details, see Table $I$.

Table 7. Minimum apparent digestibility of Ispaghula husk (Isogel) in apparently healthy adult subjects during the control period and the experimental period

\begin{tabular}{cccc} 
Subject & \multicolumn{3}{c}{ Non-cellulosic polysaccharide } \\
\cline { 2 - 3 } no.* & Hexose & Pentose & Uronic acids \\
I & $1 \cdot 0$ & 0.995 & 0.995 \\
2 & 0.680 & 0.550 & 0.850 \\
3 & 0.920 & 0.940 & 0.960 \\
4 & 0.890 & 0.750 & 0.930 \\
& $*$ For details, see Table $\mathrm{I}$. &
\end{tabular}

Table 8. Apparent digestibility of nutrients and energy for apparently healthy adult subjects during the control period and the experimental period when they were given Ispaghula husk (Isogel)

\begin{tabular}{rcccc} 
Subject* & Nitrogen & Fat & Ash & Gross energy \\
IC & 0.897 & 0.967 & 0.832 & 0.952 \\
E & 0.825 & 0.914 & 0.624 & 0.905 \\
$2 \mathrm{C}$ & 0.887 & 0.957 & 0.756 & 0.943 \\
$\mathrm{E}$ & 0.882 & 0.949 & 0.697 & 0.919 \\
$3 \mathrm{C}$ & 0.870 & $0.94 \mathrm{I}$ & 0.763 & 0.923 \\
$\mathrm{E}$ & 0.893 & 0.939 & 0.772 & 0.934 \\
4C & 0.884 & 0.939 & 0.775 & 0.934 \\
$\mathrm{E}$ & 0.893 & 0.926 & 0.714 & 0.924 \\
& \multicolumn{3}{c}{ C, Control; E, experimental. } \\
* For details, see Table I.
\end{tabular}

fibre which contrasted with the considerable variation between individuals during the experimental period. Total fibre digestibility decreased in subject nos. I, 2 and 4 but increased in subject no. 3 . The greatest variation was in the digestibility of the non-cellulosic polysaccharide pentoses which ranged from 0.40 to 0.80 . Cellulose digestibility fell in all subjects, particularly in subject no. 2, where it was only $0 \cdot 10$.

The values for the apparent digestibility of Isogel, shown in Table 7, are derived indirectly. Water-soluble non-cellulosic polysaccharides were virtually absent from the control faeces, indicating complete digestibility of those derived from foods. Isogel polysaccharides are almost totally water-soluble so the small amount of water-soluble fibre 
components which were measured in the experimental faeces were probably derived from the Isogel. The values for Isogel digestibility are all quite high, particularly in subject nos. I and 3; subject no. I appeared to digest Isogel completely.

\section{Apparent digestibility of energy and nutrients}

The values are given in Table 8 . Only subject no. I showed decreases in the digestibility of energy, $\mathrm{N}$ and fat during the experimental period. Subject nos. 2 and 4 showed small decreases in the digestibility of energy and fat but in subject no. 3 apparent digestibility was as high during the experimental period as during the control.

\section{DISCUSSION}

An increase in faecal bulk is brought about by an increase in one or both of its components; water and solids. The increase in solid matter could be due to extra unavailable carbohydrate or extra available nutrients such as protein, fat or minerals. Finally there is that component of the solid material that is very difficult to define and measure such as bacterial debris.

In this experiment three of the subjects showed a considerable increase in total faecal weight when their fibre consumption was doubled by the Isogel supplement. These subjects all showed an increased excretion of water but the proportion of water in the faeces was raised only in subject nos. 2 and 4 . These subjects have been shown to possess the least capacity for digesting Isogel (Table 7) especially the pentose component; it would appear that the hydrophillic polysaccharide reaching the faeces increased the extent of hydration. Faecal water was shown to be very well correlated with both total faecal fibre $(r 0.906$; $P<0.001)$ and faecal pentoses $(r 0.764 ; P<0.001)$.

\section{Apparent digestibility of fibre}

The values for apparent digestibility of the fibre in the control diets are in good agreement with those reported by other workers, generally coming in the upper half of the ranges given (Williams \& Olmsted, 1936; Hummel et al. 1943; Southgate \& Durnin, 1970). The values for cellulose digestibility are much higher than those reported by Southgate \& Durnin (1970) but these authors measured cellulose and lignin together. In the present investigation there was no measurable lignin in the diets although a small 'lignin' fraction was collected from the faeces.

The introduction of a fibre supplement in this present study resulted in much more individual variation in the apparent digestibility of the total fibre in the diet. This reflected the way in which the individuals or rather, their gut microflora, reacted to the ingestion of a novel, unavailable polysaccharide. Between subject nos. 2 and 4 there was a twofold difference in the quantity of fibre disappearing from the gut during transit. The most striking feature of the values for apparent digestibility of the fibre components during the experimental period is the fall in cellulose digestibility. This cannot be accounted for by the contribution from Isogel, which contains virtually no cellulose, the extra faecal cellulose must therefore be derived from food sources. Some kind of interaction between Isogel and the food-derived fibre is indicated. The high values for the digestibility of Isogel, shown in Table 7, together with the reduced apparent digestibility of total fibre during the experimental period, indicate that Isogel has the effect of not only reducing the digestibility of cellulose but also that of the dietary non-cellulosic polysaccharides. The results given in Table 7 are, therefore, the minimum values for the apparent digestibility of the Isogel polysaccharides. The increase in faecal fibre during the experimental period is therefore derived more from dietary sources other than the fibre supplement itself. 
Table 9. Increase $(\mathrm{g} / \mathrm{d})$ in faecal solids and faecal fibre during experiment periods for apparently healthy adult subjects during the control period and the experimental period when they were given Ispaghula husk (Isogel)

$\begin{array}{ccc}\begin{array}{c}\text { Subject } \\ \text { no.* }\end{array} & \text { Faecal solids } & \text { Faecal fibre } \\ \text { I } & 35 & 8 \cdot 5 \\ 2 & 27 & 18 \cdot 3 \\ 3 & 3 & 2 \cdot 4 \\ 4 & \text { IO } & 8 \cdot 3 \\ & \text { * For details, see Table I. }\end{array}$

It would appear that Isogel provides a more favourable substrate for the action of the intestinal microflora than dietary sources of fibre, particularly cellulose. This might be expected in view of the fact that whereas dietary polysaccharides are still, to a certain extent, enclosed within the plant cell wall structure and only partly water-soluble, Ispaghula is an isolated exudate of plant cell walls and thus without protection from attack. The lowest cellulose digestibility found during the experimental period was in the subject who showed the least degradation of Isogel; subject no. 2. Conversely, the highest cellulose digestibility was found in subject no. 3 who also had a very high digestibility for Isogel. It would appear that while the microflora are still saturated with Isogel substrate they do not attack cellulose. When the supply of Isogel is diminished then degradation of cellulose commences.

\section{Apparent digestibility of nutrients}

It is generally found that the increase in faecal solids brought about by the ingestion of extra fibre is more than can be accounted for merely by the presence of undegraded fibre in the faeces. Table 9 shows that, in this investigation, the discrepancy was most marked in subject no. I. In this subject only were there significant decreases in the apparent digestibility of energy, $\mathrm{N}$ and fat. Subject nos. 2 and 4 showed reduced digestibilities of energy and fat but these changes were very small compared with subject no. I.

In general these results do not support the accepted belief that an increase in the fibre in the diet inevitably results in a reduction in the apparent digestibility of nutrients (Widdowson, 1967). This has been demonstrated by other workers (McCance \& Widdowson, 1947; Southgate \& Durnin, 1970) but on these previous occasions the fibre increase brought about qualitative changes to the diet.

\section{The mechanism of faecal bulking}

The mechanism whereby fibre exerts its effect on the bulk of the faeces has been debated for many years. There are two prevailing theories; that faecal bulking is brought about by the physical presence of the fibre (Cowgill \& Sullivan, 1933) or that it is due to the cathartic effect of the products of bacterial degradation in the colon (Williams \& Olmsted, I936).

Both these theories can be accommodated by the results of this investigation. Bulking effected mainly by an increased proportion of faecal water was certainly brought about by the presence of undigested fibre in subject nos. 2 and 4 . On the other hand it could be postulated that, in subject no. I, the products of bacterial degradation of the fibre supplement increased the faecal excretion of material other than fibre. However, in subject no. 3 who also showed a very high digestibility for Isogel, there was little evidence of any increase in faecal bulk. 
The results of this investigation have shown that there is no generalized, predictable response to the ingestion of a fibre supplement. The four subjects whose behaviour was investigated displayed four individual responses to the novel polysaccharide. These results were particularly striking when contrasted with the lack of variation observed during the control balance period.

C.J.P. acknowledges receipt of a scholarship from the Medical Research Council during the period of research.

\section{REFERENCES}

Burkitt, D. P., Walker, A. R, P. \& Painter, N. S. (1972). Lancet ii, 1408.

Cowgill, G. R. \& Sullivan, A. J. (1933). J. Am. med. Ass. 100, 795.

Durrington, P. N., Manning, A. P., Bolton, C. H. \& Hartog, M. (1976). Lancet ii, 394.

Eastwood, M. A., Kirkpatrick, J. R., Mitchell, W. D., Bone, A. \& Hamilton, T. (I973). Br. Med. J. iv, 392.

Hummel, F. C., Shepherd, M. L. \& Macy, I. G. (1943). J. Nutr. 25, 59.

Jenkins, D. J. A., Hill, M. S. \& Cummings, J. H. (1975). Am. J. clin. Nutr. 28, 1408.

McCance, R. A. \& Widdowson, E. M. (1947). J. Hyg., Camb. 45, 59.

Norris, F. W. \& Preece, I. A. (1930). Biochem. J. 24, 59.

Southgate, D. A. T. (1969). J. Sci. Fd Agric. 2o, 331.

Southgate, D. A. T. (1971). J. Sci. Fd Agric. 22, 590.

Southgate, D. A. T. (1976). Determination of Food Carbohydrates. London: Applied Science Publishers.

Southgate, D. A. T. \& Durnin, J. V. G. A. (1970). Br. J. Nutr. 24, 5 I 7.

Trowell, H. C., Southgate, D. A. T., Wolever, T. M. S., Leeds, A. R., Gassull, M. A. \& Jenkins, D. J. A. (1976). Lancet i, 967.

Walters, R. L., McLean Baird, I., Davies, P. S., Hill, M. J., Drasar, B. S., Southgate, D. A. T., Green, J. \& Morgan, B. (1975). Br. med. J. ii, 536 .

Widdowson, E. M. (1967). In The Composition of Foods, p. 17I [R. A. McCance and E. M. Widdowson, editors]. London: H.M.S.O.

Williams, R. D. \& Olmstead, W. H. (I936). J. Nutr. Ir, 433. 